Original Article

\title{
STRESS AND BURNOUT ASSESSMENT AMONG POST GRADUATE DENTAL STUDENTS
}

\author{
Aditya Shetty ${ }^{1}$, Amrith Shetty ${ }^{2}$, Mithra N Hegde ${ }^{3}$, Dhanya Narasimhan ${ }^{4} \&$ Shishir Shetty $^{5}$ \\ ${ }^{1}$ Reader, ${ }^{3}$ Professor \& HOD, ${ }^{4}$ Post Graduate, ${ }^{5}$ Professor, Department of Conservative Dentistry \& Endodontics, A B \\ Shetty M emorial Institute of Dental Sciences, Nitte University, M angalore, Karnataka, India, ${ }^{2}$ Consultant Psychiatrist, \\ Cadwaladr University, Local Health Board, Swn-y-coed,Grove road,Wrexham,Zip code LL11 IDD ,UK Betsi \\ Correspondence : \\ Dhanya Narasimhan \\ Post Graduate, Department of Conservative Dentistry \& Endodontics, A B Shetty M emorial Institute of Dental Sciences, Nitte \\ University, Mangalore - 575 018, Karnataka, India. \\ M obile : +91 7204224365 E-mail : dhanya.narasimhan@gmail.com
}

\section{Abstract:}

Context: High levels of stress and burnout affect the academic, and clinical learning process and long term health of the individual.

Aims: The aim of the study was to assess stress and burnout among post graduate dental students in a dental college in India

Settings and Design : 82 post graduate dental students enrolled in the MDS programme in a dental school in India completed the Graduate Dental Environment Stress (GDES) questionnaire and Maslach Burnout Inventory. Burnout was assessed in three domains Emotional Exhaution, Depersonalization and Personal Accomplishment

Statistical analysis used : Summary statistics (proportions, mean and standard deviation) were used to summarize the responses to the Graduate Dental Environment Stress (GDES) questionnaire and Maslach Burnout Inventory

Results : The statistical analysis revealed that the mean overall score on GDES 30 stress questionnaire was 2.28. Top three stressors among the Postgraduate students was lack of leisure time, examinations and assessments, and insecurity regarding professional future. Females had significantly higher stress rates . $21 \%$ of respondents were "cases of burnout" in the Emotional Exhaustion (EE) component, 29 \% were "burnout" cases of Depersonalization (DP) while 54\%were "burnout" cases in the Personal Accomplishment (PA) domain

Conclusions : M oderate to high levels of stress and burnout were detected among this study sample. There is a need to come up with effective strategies in the postgraduate curriculum to tackle stress and burnout.

Keywords : Stress, burnout, dental postgraduates, education

Key Message : Postgraduate dental program is a specialized course which can be quite challenging physically and mentally. Stress and burnout are detrimental to the learning process. So it is important to identify the domains of maximum stress and burnout and come up with efficient strategies to tackle it.

\section{Introduction :}

Dental education is a highly demanding and challenging course placing heavy demands on the mental resources of students making them vulnerable to high levels of stress. Stress describes external demands (physical and mental)

Access this article online Quick Response Code

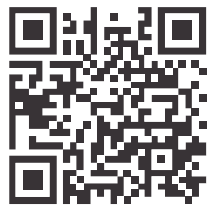
on an individual's physical and psychological wellbeing. ${ }^{1}$ Some dose of stress is beneficial and acts as a driving force for improved performance, but the persistence of long term stress can be debilitating.
Studies have shown that in comparison to the general population, dental students have been reported to experience increased levels of anxiety and depres-sion at times approaching levels seen in general medical patients judged psychiatrically ill. ${ }^{2} \mathrm{~A}$ study conducted comparing chronic stress between medical and dental students concluded that chronic stress was more pronounced among dental students. ${ }^{3}$

Post graduate training in dental science is a complex educational experience. The residents of all specialties are expected to train clinically, complete research assignments and participate in teaching programme. Apart from this, long working hours, additional strain of financial issues, 
family obligations and future employment uncertainty add to substantial stress circumstances. ${ }^{4}$ As many studies show that stress and anxiety are predictors of academic and clinical performance it becomes all the more important to assess the stress levels. ${ }^{5,6}$

This study aimed to evaluate the mental health of postgraduate students in a dental college in India specifically with respect to stress and burnout. This adds to the knowledge base from the findings from similar studies in other countries - Switzerland ${ }^{7}$, United Kingdom ${ }^{8}$, Spain ${ }^{9}$ and Greece $^{10}$. We are not aware of any similar studies among postgraduate dental students in the Indian population.

\section{Subjectsand Methods:}

All postgraduate dental students enrolled in the MDS program of a dental college in India in the year 2011-2013 comprised the target population and were requested to participate in the study $(n=126)$. The study sample included residents in six departments: Conservative dentistry and Endodontics, Orthodontics, Oral and Maxillofacial surgery, Pedodontics, Periodontics, Prosthodontics, Oral medicine and radiology and Oral pathology. The MDS program is a 36 month programme which when successfully completed leads to a Masters degree in Dental Surgery (MDS) specific to each department. Stress and burnout were separately evaluated. To measure perceived stress, a modified version of the Graduate Dental Environment Stress (GDES30) scale was used. ${ }^{11}$ The participants were administered a questionnaire in English language. Postgraduate students were invited to complete the questionnaires with pen or pencil and completion required approximately 20 minutes. The questionnaire was anonymous and participation was voluntary.

The questionnaire basically consisted of 30 statements pertaining to various sources of stress perceived by the dental postgraduates on a daily basis. The statements were to be rated on a 4 point likert scale as 1: "not stressful at all", 2: "somewhat stressful",3 "quite stressful",4: "very stressful".
To quantify burnout the 22-item Maslach Burnout Inventory (M BI) (Maslach et al., 1996) was employed, as used in previous investigations to measure burnout. ${ }^{7,8,11}$ This questionnaire is a modification of the list of stressor items listed by Garbee and colleagues in $1980 .{ }^{12}$ The three dimensions of burnout that were measured by this 22 point scale were Emotional Exhaustion (EE; nine items), Depersonalization (DP; five items) and Personal Accomplishment (PA; eight items). Participants were asked to rank these items on a seven-point Likert scale where 0 means "never", 1: "a few times a year",2: "monthly" ,3: "a few times a month" ,4: "weekly" , 5: "a few times a week" and 6 : "everyday". The subscale score thresholds that were recommended by the $\mathrm{MBI}$ manual were used to identify individuals who met the criteria of burnout "cases"- EE: > $26, \mathrm{DP}:>12$, and $\mathrm{PA}:<32.13$

Summary statistics (proportions, mean and standard deviation) were used to summarize the responses to the thirty stress items, as well as the participants' demographic information. Subsequently, overall mean GDES30 and M BI subscale scores were computed.Cronbach's alpha was computed for the GDES as a measure of its internal consistency , proportions of burnout "cases" were calculated among the entire sample of residents and stratified according to year of study (first, second, and third), age and gender

\section{Results:}

Out of the 126 postgraduates contacted, 82 completed the stress survey questionnaire and 72 completed the burnout questionnaire. The Cronbach's alpha was 0.876 for the stress questionnaire. Respondents had a mean age of 27 and were balanced in terms of age and gender. The specialty distribution of the respondents and the year of study are depicted in Table I.

The mean overall score was GDES30 was $2.28(\mathrm{SD}=0.09)$, the vast majority of answers were in range between 2 (somewhat stressful) and 3 (quite stressful). Distribution of individual responses to the thirty statements, as well as mean scores and ranking of the stress factors are given in Table II .Top three stressors overall among the Postgraduate 
students was examinations and assessments, lack of time for leisure activities, and insecurity regarding professional future. Meeting research requirements, financial issues and amount of assigned reading material were the next three factors for stress. There was no significant difference in the perceived stress among the three years. However multiple linear regression analysis indicated that stress due to fear of failure while treating complex cases, and difficulty of communication with patients was maximum in the first year postgraduates and decreased with subsequent years .Overall females had slightly higher stress rates than males which was significantly higher in terms of response to stress induced by amount of assigned readings, difficulty of assigned readings, examinations/assessments, learning clinical/surgical techniques, and lack of leave and holiday days allowed. The mean score of perceived stress was higher in the younger age group (2.31 vs 2.23 ). With regard to burnout $21 \%$ of respondents were "cases of burnout" in the emotional exhaustion component, Table III the proportion was higher for depersonalization (29\%) while personal accomplishment was lowest with 54\% of the postgraduates burnout cases with inadequate sense of personal accomplishment. There was however no significant difference in burnout cases among the three years of postgraduates.

Table. I Descriptive information of the 82 dental postgraduate students $\mathrm{N}$ (Percent)

\begin{tabular}{|c|c|c|}
\hline $\begin{array}{l}\text { Demographics } \\
\text { Female } \\
\text { Male } \\
\text { Age (Years, mean) }\end{array}$ & \multicolumn{2}{|c|}{$\begin{array}{l}41(50 \%) \\
41(50 \%) \\
27\end{array}$} \\
\hline $\begin{array}{l}\text { Years of study } \\
\text { First } \\
\text { Second } \\
\text { Third }\end{array}$ & \multicolumn{2}{|c|}{$\begin{array}{l}\text { No of participants } \\
29(35.36 \%) \\
27(32.9 \%) \\
26(31.7 \%)\end{array}$} \\
\hline $\begin{array}{l}\text { Program type } \\
\text { Conservative dentistry } \\
\text { M axillofacial surgery } \\
\text { Periodontics } \\
\text { Pedodontics } \\
\text { Orthodontics } \\
\text { Prosthodontics } \\
\text { Oral medicine radiology } \\
\text { Oral pathology }\end{array}$ & $\begin{array}{l}20 \\
6 \\
6 \\
14 \\
8 \\
18 \\
6 \\
4\end{array}$ & $\begin{array}{l}(24.39 \%) \\
(7.31 \%) \\
(7.31 \%) \\
(17.07 \%) \\
(9.75 \%) \\
(21.95 \%) \\
(7.31 \%) \\
(4.87 \%)\end{array}$ \\
\hline
\end{tabular}

Table II : Distribution of responses to the thirty stressors of the Graduate Dental Environment Stress (GDES30) questionnaire, with mean scores and standard deviation and ranking of the items among the 82 postgraduate dental students

\begin{tabular}{|l|c|c|c|c|c|c|c|c|}
\hline Stress Items & $1^{*}$ & $2^{*}$ & $3^{*}$ & $4^{* *}$ & M ean & $\begin{array}{c}\text { Standard } \\
\text { Deviation }\end{array}$ & Rank $^{* * *}$ \\
\hline Q1 Amount of assigned reading material & & & & & & & \\
\hline Q2 Difficulty of understanding course reading material & 15 & 31 & 33 & 3 & 0 & 2.29 & 0.80 & 14 \\
\hline Q3 Competition for higher performance & 26 & 21 & 22 & 11 & 2 & 2.17 & 1.09 & 20 \\
\hline Q4 Patients coming late /missing appointments & 9 & 26 & 26 & 18 & 3 & 2.57 & 1.06 & 8 \\
\hline Q5Examinations/assessment & 14 & 19 & 20 & 29 & 0 & 2.78 & 1.11 & 1 \\
\hline Q6 Collaboration with Para medical staff ( lab technician) & 40 & 20 & 12 & 10 & 0 & 1.90 & 1.06 & 26 \\
\hline Q7 Learning laboratory techniques & 23 & 26 & 24 & 9 & 0 & 2.23 & 0.98 & $18-19$ \\
\hline Q8 Learning clinical/surgical techniques & 32 & 21 & 21 & 5 & 3 & 1.91 & 1.02 & 25 \\
\hline Q9 Lack of adequate staff in the clinic & 46 & 14 & 11 & 10 & 1 & 1.79 & 1.09 & 30 \\
\hline Q10 Lack of confidence to be a successful resident & 41 & 21 & 7 & 11 & 2 & 1.80 & 1.09 & 29 \\
\hline Q11 Lack of confidence in meeting patient expectations & 36 & 21 & 16 & 6 & 3 & 1.82 & 1.02 & 28 \\
\hline Q12 M eeting research requirements & 10 & 25 & 32 & 15 & 0 & 2.63 & 0.92 & $4-5$ \\
\hline Q13 Policies and regulations of the course & 13 & 17 & 38 & 12 & 2 & 2.54 & 1.00 & 10 \\
\hline Q14 Obtaining adequate clinical experience & 23 & 21 & 27 & 10 & 1 & 2.26 & 1.04 & 16 \\
\hline Q15 Completing graduation requirements & 17 & 20 & 33 & 11 & 1 & 2.43 & 1.00 & 12 \\
\hline Q16 Lack of input in administrative issues of the program & 30 & 18 & 19 & 13 & 2 & 2.13 & 1.15 & 21 \\
\hline Q17Insecurity regarding professional future & 9 & 27 & 30 & 16 & 0 & 2.64 & 0.92 & 3 \\
\hline Q18Financial issues & 18 & 19 & 16 & 28 & 1 & 2.63 & 1.20 & $4-5$ \\
\hline Q19 Lack of time for leisure activities & 17 & 11 & 22 & 30 & 2 & 2.74 & 1.22 & 2 \\
\hline Q20 Inconsistency of feedback between different instructors & 20 & 25 & 23 & 13 & 1 & 2.32 & 1.05 & 13 \\
\hline Q21Availibility of faculty to work up cases & 29 & 24 & 18 & 9 & 2 & 2.03 & 1.05 & 22 \\
\hline Q22Difficulty in communication with patients & 26 & 14 & 22 & 17 & 3 & 2.29 & 1.22 & 15 \\
\hline
\end{tabular}




\begin{tabular}{|l|c|c|c|c|c|c|c|c|}
\hline Stress Items & $1^{*}$ & $2^{*}$ & $3^{*}$ & $4^{*}$ & $\mathrm{n}^{* *}$ & M ean & $\begin{array}{c}\text { Standard } \\
\text { Deviation }\end{array}$ & Rank $^{* * *}$ \\
\hline Q23 Lack of leave and holidays & 15 & 25 & 22 & 18 & 2 & 2.47 & 1.10 & 11 \\
\hline Q24 Fear of failure when treating complex cases & 15 & 33 & 24 & 8 & 2 & 2.25 & 0.95 & 17 \\
\hline Q25 Neglect for personal cases & 14 & 24 & 20 & 22 & 2 & 2.56 & 1.18 & 9 \\
\hline Q26 Awareness of own competences and limitations & 19 & 28 & 28 & 6 & 1 & 2.23 & 0.93 & $18-19$ \\
\hline Q27 Collaboration with part time faculty & 32 & 26 & 15 & 7 & 2 & 1.91 & 1.00 & 24 \\
\hline Q28 Doing case presentations to patients & 28 & 25 & 19 & 7 & 3 & 1.98 & 1.03 & 23 \\
\hline Q29 Doing presentations in seminar activities & 16 & 19 & 22 & 23 & 2 & 2.58 & 1.16 & 7 \\
\hline Q30 Collaboration with other specialties282918431.900.9527 & & & & & & & & \\
\hline
\end{tabular}

* Percent calculated among non-missing responses, where 1: not stressful at all, 2: somewhat stressful, 3: quite stressful, 4: very stressful

** Number of missing responses/ not aplicable

*** Items ranked from highest to lowest mean score

Table III : Distribution of perceived stress (GDES30 mean score and standard deviation [SD]) and burnout (M BI subscale mean scores and SD, and percent of "high" or "low scorers", or "cases") among the entire sample, and stratified by age, gender and year of study among 72 postgraduate students

\begin{tabular}{|l|c|c|c|c|c|c|c|c|}
\hline & & $\begin{array}{c}\text { Perceived stress } \\
\text { GDES mean }\end{array}$ & $\begin{array}{c}\text { Emotional } \\
\text { exhaustion } \\
\text { Mean (SD) }\end{array}$ & \% high & $\begin{array}{c}\text { Depersonalization } \\
\text { Mean ( SD) }\end{array}$ & $\begin{array}{c}\text { \% high } \\
\text { accomplishment } \\
\text { Mean (SD) }\end{array}$ & Personal & \% reduced \\
\hline Age & Overall & $2.28(0.09)$ & $17.88(11.25)$ & $21 \%$ & $8.54(8.67)$ & $29 \%$ & $29.37(10.14)$ & $54 \%$ \\
\hline & $<7$ & $2.31(0.10)$ & $18.14(11.11)$ & $21 \%$ & $9.31(9.30)$ & $31 \%$ & $30.55(10.73)$ & $46 \%$ \\
\hline Gender & $>27$ & $2.23(0.11)$ & $17.40(11.71)$ & $21 \%$ & $7.08(7.29)$ & $25 \%$ & $27.16(8.69)$ & $71 \%$ \\
\hline & Male & $2.20(0.11)$ & $17.57(11.34)$ & $25 \%$ & $9.8(7.12)$ & $31 \%$ & $30.57(6.45)$ & $51 \%$ \\
\hline Year of study & Female & $2.36(0.11)$ & $18.18(11.34)$ & $13 \%$ & $7.3(3.42)$ & $27 \%$ & $28.54(8.95)$ & $70 \%$ \\
\hline & First & $2.31(0.13)$ & $18.61(13.73)$ & $25 \%$ & $10.69(10.31)$ & $30 \%$ & $29.30(12.26)$ & $48 \%$ \\
\hline & Second & $2.22(0.12)$ & $17.08(8.38)$ & $8 \%$ & $6.86(8.58)$ & $30 \%$ & $30.95(8.29)$ & $56 \%$ \\
\hline & Third & $2.30(0.11)$ & $17.86(11.07)$ & $27 \%$ & $7.78(6.35)$ & $27 \%$ & $27.86(9.33)$ & $59 \%$ \\
\hline
\end{tabular}

* Proportions of burnout "cases" were calculated using the thresholds used in the Maslach Burnout Inventory - high emotional exhaustion score: $>26$

** High depersonalization score: $>12$

*** Reduced personal accomplishment score: $<32$

\section{Discussion :}

The study found moderate to high levels of stress and burnout faced by post graduates students in their three years of training. The overall stress score being 2.28 was higher among this study group of dental postgraduates when compared to a similar study on Greek dental residents $(2.1)^{7}$

"Examinations and assessment" "lack of time for leisure activities" and "insecurity regarding professional future" were top stressors among the study group. This is not surprising considering the meticulous and strict nature of the course. The stress of examination and assessment can be attributed to the competitive nature of the course, and the fear of failing the course requirement. Previous findings of similar studies rank "lack of leisure time" and "completing graduation requirements" the highest stressors. ${ }^{14,15,16}$ Our data did not reveal stress and burnout to be linked to the study year, unlike studies conducted in European dental residents. ${ }^{9,17}$ This could be explained on two grounds. First, the timing of the survey corresponded to almost ten months from the beginning of the academic year. Hence, the students in the first year would have had significant exposure to the professional environment and its attendant mental demands including facing the taxing clinical workload. There is a possibility that although the course burden increases with the year, the coping skills may also be improve with time. This could also be the reason that burnout is consistently higher in the lower age group (<26years). There is also the limitation of limited sample size. In any case, it must be acknowledged that the typically small size of all studies in the field, limits their 
between-subgroups inferential potential. ${ }^{9}$ Increased stress of communication with patients among first year postgraduates can be justified, because India has a multi linguistic population. The setting of the study is a dental college situated at the border of two states with the population speaking various dialects. Gender has been considered to be an important factor in influencing the extent of psychological symptoms. The female students in our study had a higher level of stress relative to their male counterparts. There is higher female stress in many studies conducted among dental and medical professionals. ${ }^{2,18,19,20,21}$ This could be attributed to socio cultural differences, different psychological attributes related to coping skills and vulnerability to life events..$^{5,22,23}$

Our study revealed high levels of burnout among the postgraduates with more than $54 \%$ of the postgraduates feeling low Personal Accomplishment and 29\% feeling burnout with Depersonalization, and $21 \%$ Emotionally Exhausted. This burnout is much higher than burnout values obtained from postgraduates in European dental schools. ${ }^{9}$ The current study set up is a dental college offering completely free dental care to all the patients irrespective of the dental care required. This is similar to most government dental hospitals where patient dental care is almost always free or at minimal cost. Such a

\section{Reference :}

1. Atkinson TM, Millar K, Kay EJ, Blinkhorn AS. Stress in dental practice. Dent Update 1991;18:60-4

2. Lloyd C, Musser LA. Psychiatric symptoms in dental students. J Nerv Ment Dis $1989 ; 177(2): 61-9$

3. Schmitter M, Liedl M, BeckJ, Rammelsberg P. Chronic stress in medical and dental education. M ed Teach 2008;30:97-99

4. Thomas N K: Resident burnout. JAM A 2004:292:2880-9

5. Sanders A E, Lushington K: Sources of stress for Australian dental students. J Dent Educ 1999;63: 688-697

6. Tedesco LA.A Psychosocial perspective on the dental education experience and student performance .J DentEdu 1986;50:601-606

7. Divaris K, Lai CS, Polychronopoulou A, Eliades T, Katsaros C. Stress and burnout among Swiss dental residents. Schweiz Monatsschr Zahnmed. 2012; 122(7-8):610-5

8. Gorter R, Freeman R, Hammen S, M urtomaa H, Blinkhorn A, Humphris G.Psychological stress and health in undergraduate dental students:fifth year outcomes compared with first year baseline results from five European dental schools. Eur J Dent Educ 2008;12:61-8

9. Humphris G, Lilley J, Kaney S, Broomfield D:Burnout and stress-related factors among junior staff of three dental hospital specialties. Br Dent 1997;183:15-21

10. Alemany Martínez A, Berini Aytés L, Gay Escoda C. The burnout syndrome and associated personality disturbances. The study in three scenario leads to an immense case load which is handled by the postgraduate dental students. A disproportion between the numbers of patients to the post graduate students can lead to quicker burnout, and more stress.

\section{Limitations of the study}

The limitations of our study are limitations inherent in the methodology i.e. a chance of misinterpretation of questions and lack of response could not be controlled. The cross-sectional approach to interpretation of stress across three years, the difference in the number of postgraduates from different subjects participating in the study are limiting factors to an accurate assessment.

\section{Conclusion:}

Our study reveals high levels of stress and burnout among post graduate dental students, which must not be overlooked. There is a need to come up with an effective strategy in the postgraduate curriculum to tackle stress and burnout .Regulating bodies for dental education should take initiatives to provide financial security and future job prospects for the students, policies to update the examination systems and make it relatively less stressful should be looked into. Addressing issues that may arise in the educational setting will help improve the academic environment and lead to superior professional training.

graduate programs in Dentistry at the University of Barcelona. Med Oral Patol Oral Cir Bucal. 2008;13:E444-50

11. Divaris K, Polychronopoulou A, Taoufik A, Katsaros C, Eliades T.Stress and burnout in postgraduate dental education. Eur J Dent Educ 2012;16:35-42

12. Garbee WH, Zucker SB, Selby GR. Perceived sources of stress among dental students. J Am Dent Assoc 1980;100:853-7.

13. M aslach C, Jackson SE, Leiter M P. M aslach Burnout Inventory M anual, Palo Alto, CA 3rd ed. Consulting Psychologists Press, Inc; 1996

14. Sofola 00, Jeboda SO. Perceived sources of stress in Nigerian dental students. Eur J Dent Educ 2006;10:20-3

15. Polychronopoulou A, Divaris K.Dental students'perceived sources of stress: a multi-countrystudy. J Dent Educ 2009;73:631-9

16. Alzahem AM, van der Molen HT, Alaujan AH, Schmidt H G Zamakhshary MH. Stress amongst dental students: a systematic review. Eur J Dent Educ 2011;15:8-18

17. Polychronopoulou A, Divaris K: A longitudinal study of Greek dental students' perceived sources of stress. J Dent Educ2010;74:524-30

18. Madhan B, Rajpurohit A, Gayathri H. Mental health of postgraduate orthodontic students in India: A multi-institution survey. J Dent Educ 2012; 76(2): 200-9.

19. Naidu RS, Adams JS, Simeon D, Persad S. Sources of stress and psychological disturbance among dental stu-dents in the West Indies. 
J Dent Educ 2002;66(9):1021-30

20. Newbury-Birch D, Lowry RJ, Kamali F. The changing patterns of drinking, illicit drug use, stress, anxiety, and depression in dental students in a UK dental school: a longitudinal study. $\mathrm{Br}$ Dent J 2002;192(11):646-9.

21. Pau A, Rowland M L, Naidoo S, AbdulKadir R, Makrynika E, M oraru R, Huang B, Croucher R.. Emotional intelligence and perceived stress in dental undergraduates: a multinational survey. J Dent Educ 2007;71(2):197-99

22. Schéle I, Hedman L, Hammarström A.Shared ambiguity but different experiences and demands among dental students - a gender perspective. Qualitative Research in Psychology 2011;8(1):1-25

23. Polychronopoulou A, Divaris K: Perceived sources of stress among Greek dental students. J Dent Educ 2005; 69: 687-92 